\title{
EXPRESSING PERSONAL MEANING IN MODERN POLITICAL DISCOURSE: LEXICAL ASPECT
}

\author{
Svetlana N. Zarezina \\ Irkutsk State University, Irkutsk, Russia
}

\begin{abstract}
The purpose of the paper is to investigate some lexical means of expressing personal meaning in political discourse based on the Russian language. We define the notion 'personal meaning' in various aspects, focus on its sources in different utterances: ambiguousness of reality, the bias in a person's objective picture of the world, creation of personal worlds in the process of creativity and constant expansion of knowledge. We draw special attention to the peculiarities of political discourse and some means of expressing personal meaning in it. In the practical part of the paper we present some vivid examples that express a personal meaning of the speaker: political lexis that can have positive and negative connotation, neologisms, borrowed words, jargonistic words, etc. Some examples of generalization as one more way of expressing personal meaning are given in the paper. The lexemes that have a general meaning may have a derogative connotation. Finally, we make a conclusion that personal meaning is a vital part of any text and a political text in particular. It expresses the intention of the author and it is usually verbalized in the text through diversity of lexical units. The results of the given research could be interesting for the investigators of the discourse and political discourse in particular on the subject of expressing personal meaning in it.
\end{abstract}

Key words: personal meaning, political discourse, sources of personal meaning, lexical units, political vocabulary, neologism, borrowing, stylistic coloring of the word.

Citation. Zarezina S.N. Expressing Personal Meaning in Modern Political Discourse: Lexical Aspect. Vestnik Volgogradskogo gosudarstvennogo universiteta. Seriya 2, Yazykoznanie [Science Journal of Volgograd State University. Linguistics], 2018, vol. 17, no. 4, pp. 163-169. (in Russian). DOI: https://doi.org/10.15688/jvolsu2.2018.4.15

УДК 81 ' $42: 32$

ББК 81.055 .51 .3

Дата поступления статьи: 27.07.2018

Дата принятия статьи: 27.08.2018

\section{ВЫРАЖЕНИЕ ЛИЧНОСТНОГО СМЫСЛА В СОВРЕМЕННОМ ПОЛИТИЧЕСКОМ ДИСКУРСЕ: ЛЕКСИЧЕСКИЙ АСПЕКТ}

\author{
Светлана Николаевна Зарезина \\ Иркутский государственный университет, г. Иркутск, Россия
}

\begin{abstract}
Аннотация. Статья посвящена проблеме выявления личностного смысла, который рассматривается как особенность политического дискурса. Раскрывается содержание понятия «личностный смысл» в разных аспектах, дается его авторское определение и характеризуются его источники: неоднозначность реальности, $\infty$ тенденциозность представления человеком объективной картины мира, создание личностных миров в про굴 цессе творчества, постоянное расширение знаний. На основе анализа опубликованных в российских СМИ журналистских текстов, содержащих прямые цитаты из речей современных политических деятелей, и текстов, созданных политиками, показано, что личностный смысл отражает целевую установку политика (автора высказывания) и реализуется при помощи определенных языковых сигналов, описанных в статье. Выявлены такие лексические средства выражения личностного смысла, как слова, относящиеся к политической ๓̈ лексике и имеющие позитивную или негативную коннотации, неологизмы, заимствования, обобщенные () номинации, обладающие яркой дерогативной окраской, слова с аксиологическим значением, стилистически
\end{abstract}




\section{МАТЕРИАЛЫ И СООБЩЕНИЯ}

маркированные лексемы (книжные и разговорные) и некодифицированные лексические единицы. Установлено, что в российском политическом дискурсе сохраняется тенденция к снижению порога приемлемости в использовании нелитературной лексики в речи политических деятелей.

Ключевые слова: личностный смысл, политический дискурс, источники личностного смысла, лексические единицы, политическая лексика, неологизм, заимствование, стилистическая окраска слова.

Цитирование. Зарезина С. Н. Выражение личностного смысла в современном политическом дискурсе: лексический аспект // Вестник Волгоградского государственного университета. Серия 2, Языкознание. 2018. - T. 17, № 4. - C. 163-169. - DOI: https://doi.org/10.15688/jvolsu2.2018.4.15

\section{Актуальность исследования личностного смысла}

Антропоцентризм, признанный в настоящее время основным методологическим подходом к анализу языковых фактов, постулирует всеобъемлющее присутствие человека в языке. Особое место в современной антропологической лингвистике занимает исследование личностных смыслов, поскольку насыщение дискурса собственным «Я» говорящего, включенность говорящего в денотативную ситуацию, отражающую особенности его личности, повышает эффективность дискурса, его воздействующий потенциал. Исследование политического дискурса, на формирование которого влияет как социальный, так и индивидуальный опыт автора, позволит расширить наши представления о природе личностного смысла, особенностях его порождения и функционирования в дискурсе данного типа.

Цель статьи состоит в выявлении лексических средств выражения данного смысла в современном русскоязычном политическом дискурсе.

\section{Теоретические основы исследования личностного смысла}

Лингвистическая теория личностного смысла восходит к теории смысла говорящего (utterer's meaning), выдвинутой П. Грайсом. Смысл говорящего трактуется как относящийся к какому-либо определенному моменту или событию и напрямую зависит от личного мира говорящего, находящегося в разной степени соотнесенности с реальным положением вещей и детерминированного целями, мотивами, установками и интенциями самого говорящего [Grice, 1989, p. 98].

Истоки изучения личностного смысла в отечественной науке восходят к работам та- ких психологов, как Л.С. Выготский, А.Н. Леонтьев и др. А.Н. Леонтьев различает «значение-в-себе» и «значение-для-меня», которое и определяет как личностный смысл. Помимо этого общего определения исследователь характеризует личностный смысл как отражение в сознании отношения мотива (деятельности) к цели (действию) [Леонтьев, 2000, c. 98-103].

В современных исследованиях понятие личностного смысла трактуется учеными с разных позиций. Так, В.В. Красных рассматривает личностный смысл в аспекте теории текста и определяет его как глубинный смысл, свернутую структуру, в основе формирования которой лежит ситуация и индивидуальное когнитивное пространство автора (его личный фонд знаний). Текст, в этой трактовке, отражает ситуацию не непосредственно, а через восприятие ситуации автором и через ее отражение в его сознании [Красных, 1998, с. 62].

Рассуждая о природе личностного смысла в политическом дискурсе, О.А. Стрелкова отмечает, что в интересах политика сделать так, чтобы заложенный в его дискурсе личностный смысл восприняли как можно больше людей. Однако проблема заключается в том, что этот смысл связан с реальностью каждого субъекта, его жизнью, представлениями, культурными ориентирами, мотивами. Поэтому, облекая свой смысл в символическую лексическую форму, политик вынужден выбирать наиболее узнаваемый или, по крайней мере, точный образ, снижая вероятность двусмысленности [Стрелкова, 2006, с. 83].

По словам А.П. Чудинова, сочетание в политическом дискурсе институционального и личностного варьируется. «Уровень институциональности сокращается в жанрах, совмещающих признаки публицистического, личностного и политического дискурса, особенно при отражении политических проблем в СМИ 
в рамках специальных жанров (репортаж, фельетон, колонка обозревателя и др.). Вместе с тем во многих случаях политики стремятся сделать свое выступление более естественным, приближающимся по своим внешним признакам к бытовому диалогу. <..> Такое построение речи производит впечатление особой доверительности, искренности, позволяет сказать больше, чем это позволяет официальная обстановка» [Чудинов, 2009, с. 45].

Характеризуя политический дискурс российского общества в последнее десятилетие XX в., А.П. Чудинов отмечает его яркость, граничащую с карнавальностью и раскрепощенность, граничащую со вседозволенностью и политическим хамством. Специфику этого дискурса в значительной степени определяют свойственные социальному сознанию концептуальные векторы тревожности, подозрительности, неверия и агрессивности, ощущение «неправильности» существующего положения дел и отсутствия надежных идеологических ориентиров, «национальной идеи», объединяющей общество [Чудинов, 2009, c. 158-190]. Выражение личностного смысла в современном политическом дискурсе исследователь связывает с особым стремлением политиков к индивидуальному «фирменному» стилю, экспрессивности.

Мы понимаем личностный смысл как состояние сознания человека, возникающее в результате соотнесенности вербального или невербального выражения с денотативной ситуацией, сконструированной говорящим / пишущим в соответствии с его интенциями на основе веры, желания, личного мнения или эмоций [Зарезина, 2004, с. 91].

Источником личностного смысла является, во-первых, неоднозначность реальности - такое положение вещей в мире, по поводу которого возможны разные мнения, предположения, гипотезы и т. п. Во-вторых, личностный смысл возникает в результате трансформаций в объективной картине мира - искажения реальности человеком, тенденциозного представления им реального положения вещей. В-третьих, его источником является «небытие», то есть особые личные миры, созданные в результате творчества, веры или эмоционально-волевого усилия их авторов и воплощенные в текстах. В-четвертых, в ка- честве источника личностного смысла выступает происходящий в каждом человеке постоянный рост живого знания, контроль личности над ним и формирование индивидуальных контекстов в общем коллективном массиве знаний [Зарезина, 2004, с. 50].

Таким образом, личностные смыслы, являющиеся частью современного политического дискурса, отражают целевую установку автора, его отношение к описываемой денотативной ситуации.

\section{Лексические средства выражения личностного смысла в русскоязычном политическом дискурсе}

Специальные исследования в области политического дискурса показывают, что его специфика создается, прежде всего, на лексическом уровне, поэтому рассмотрим именно лексические средства выражения личностного смысла в современном русскоязычном политическом дискурсе. Материалом для работы послужили тексты журналистов, посвященные политической тематике и содержащие прямые цитаты из высказываний политических деятелей и тексты, созданные людьми, профессионально занимающимися политической деятельностью, то есть политиками.

I. Выражение личностных смыслов говорящего обеспечивается употреблением слов, относящихся к политической лексике. Они могут приобретать положительные или отрицательные коннотации. Примером их реализации служат контексты, в которых используется центральный для политики термин государство:

(1) Для России характерна традиция сильного государства (Путин);

(2) Любую чудную страну испортить можно государством (Порошенко).

В примере (1) данный термин имеет положительную коннотацию и обозначает государство как политическую целостность, созданную многонациональной общностью на территории России. В примере (2) лексема государство имеет негативную коннотацию и обозначает совокупность официальных органов власти, действующих на территории современной Украины. 


\section{МАТЕРИАЛЫ И СООБЩЕНИЯ}

Часто слова, используемые политиками, совпадают в области денотатов, но различаются по коннотации: сепаратисты и освободители, контртеррористическая операция и война. Например, действия России по отношению к Украине политики называют освобождением, вторжением, оккупаџией или агрессией в зависимости от того, какая из конфликтующих сторон входит в «свой мир» для говорящего.

II. Выражение личностного смысла происходит в результате использования неологизмов, в том числе и окказионализмов. Примерами могут служить такие единицы, как пропутинский, антитеррористический, нормандский формат (название, закрепившееся за дипломатической группой высокопоставленных представителей Германии, России, Украины и Франции по урегулированию кризиса на Донбассе, работа которой началась после встречи глав перечисленных государств 6 июня 2014 г. в ходе мероприятий в честь 70-летия высадки союзников в Нормандии).

III. В современном политическом дискурсе продолжается диктуемый как потребностями общества, так и политической ситуацией процесс заимствования иноязычных слов и образование варваризмов.

Значительная часть заимствований уже прочно вошла в русский язык. Кроме того, обращает на себя внимание широкое использование в российском политическом дискурсе и неассимилированных английских слов и выражений (делинквент, месседж, истеблишмент, брифинг, денонсация и др.):

(3) Никакого прайвеси у чиновников, когда они в служебных автомобилях, быть не должно (Общество синих ведерок).

Заимствованные слова, употребленные в речи, безусловно, придают ей образность и выражают личное отношение говорящего к предмету высказывания.

IV. Способом выражения личностного смысла в современном политическом дискурсе является навешивание ярлыков, в качестве которых чаще всего выступают термины-идеологемы, то есть слова, содержащие в своих значениях идеологический компонент. Некоторые из них имеют пейоративную коннотацию (гитлеровиы, оккупанты, экстремисты, сталинисты), а другие являются нейтральными (либераль, патриоты, ЛДПРовиьь).

V. Нередко в политическом дискурсе используется такой способ образования новых слов, как словосложение. Такие лексические единицы, как правило, имеют негативную коннотацию (либерасты, путлер, дерьмократ, губернизачия, азиатизачия).

VI. Для выражения личностного смысла весьма широко используются стилистически маркированные слова. С одной стороны, это книжная, «высокая» лексика (взывать, нерушимый, огласить и др.), а также клише и штампы, характерные для публицистического стиля (гневный протест, мировое сообщество, встреча на высшем уровне и др.), с другой - разговорная и просторечная лексика, а также сленг, жаргон и др. Примерами использования такой лексики могут послужить высказывания российских лидеров:

(4) Вышли, не имея права, - получите по башке дубиной (Колесников);

(5) Но это все-таки не блины печь! (Колесников);

(6) Подрыв устоев отечественной экономики провокационными призывами «не кошмарить бизнес»? (Камышев).

Исследователи современного политического дискурса отмечают, что в последнее время значительно понизился порог приемлемости в использовании нелитературной лексики, в том числе вульгарных и бранных слов. Некоторые участники политического процесса, бравируя «близостью к народу», позволяют себе выражения, за которые обычных граждан, по меньшей мере, штрафуют [Чудинов, 2009, с. 243]. Экспликация личностного смысла посредством использования разговорных, просторечных и др. стилистически сниженных слов помогает достичь выразительности, отражает особое эмоциональное состояние говорящего, способствует влиянию на адресата. Например:

(7) Мы будем оставаться государством-уродом, страной идиотов, землей сумасшедших (Жириновский);

(8) Нацболы? Засранцы они. Да мало ли унас таких клопов вонючих? У них одна цель - повонять и уйти (Репортаж со съезда); 
(9) Я думаю, что Сечин тоже уже всё. Репутация его на западе уже кончена. Все знают, что это крокодил такой, что он ЮКОС похитил в свое время и с Путиным они дружбаны (Троицкий);

(10) Все вопросы им тут написали на бумажке, всякие дурацкие дежурные вопросы (Сапожников).

Следует особо отметить, что использование коллоквиализмов, сленгизмов и вульгаризмов стало вполне допустимым в современных СМИ. Политики используют слова из криминального жаргона, например:

(11) В туалете поймаем, мы в сортире их замочим, в конце концов. Все, вопрос закрыт окончательно (Сербицкий);

(12)Немножко типа подраскрутить (Колесников);

(13) Наркоденьги, которые «закачивали» в бюджет (Рискин).

VII. Выражение личностного смысла может осуществляться посредством лексических единиц (слов и устойчивых словосочетаний), приобретающих в контексте уничижительное значение: кое-как, кое-кто, так называемый, позиционируюший себя, с позволения сказать, а также дейктических слов эти, там, те, являющихся показателями недоверия к оппоненту и умаления его значимости.

VIII. Обобщенные номинации, которые заменяют слова, называющие конкретных участников события и объекты, связанные с ними, являются еще одним средством выражения личностного смысла. Они увеличивают неопределенность как в описании, так и в интерпретации конкретной ситуации или в характеристике лица. Кроме этого, такие обобщенные номинации обладают дерогативной окраской:

(14) Верные путинцы: всего лишь реинкарнированные власовцы (Мономах);

(15) Эти навязчивые ковальчуки (Троицкий);

(16) ... этих путинскихприживалок(Троицкий).

IX. Для выражения личностного смысла говорящего широко используется аксиологическая лексика плодотворный, беспрецуедентный, пагубный, взаимопомощь, единение, долготерпение и др.

\section{Выводы}

Итак, личностные смыслы являются важной частью содержания любого, в том числе и политического дискурса. Они отражают интенцию автора и реализуются при помощи определенных языковых сигналов. В политической речи выражение личностного смысла осуществляется, прежде всего, посредством употребления различных лексических единиц: слов, имеющих как позитивную, так и негативную коннотации, неологизмов, заимствований, жаргонизмов, аксиологической лексики. Политики используют обобщенные номинации, которые обладают ярко выраженной дерогативной окраской. Кроме того, особенностью современной политической коммуникации является использование лексических ресурсов некодифицированных сфер языка.

\section{СПИСОК ЛИТЕРАТУРЫ}

Зарезина С. Н., 2004. Устойчивые личностные смыслы в аспекте межкультурной коммуникации (на материале статей о России в англоязычной прессе за 1991-2004 гг.) : дис. ... канд. филол. наук. Иркутск. 236 с.

Красных В. В., 1998. От концепта к тексту (к вопросу о психолингвистике текста) // Вестник Московского университета. Сер. 9. Филология. № 1. C. 53-70.

Леонтьев А. Н., 2000. Лекции по общей психологии. М. : Смысл. 511 с.

Стрелкова О. А., 2006. Особенности современного женского политического дискурса (на примере речевых портретов женщин-политиков) : дис. ... канд. филол. наук. Курск. 183 с.

Чудинов А. П., 2009. Современная политическая коммуникация. Екатеринбург : Урал. гос. пед. ун-т. 292 с.

Grice H. P., 1989. Studies in the Way of Words. Cambridge : Harvard University Press. 394 p.

\section{ИСТОЧНИКИ}

Жириновский - Жириновский В. В. ЛДПР. Уроды. М. : Издание ЛДПР, 2011. 160 с.

Камышев - Камышев Д. Проект «Ну, погоди!» // Коммерсант.ru. URL: http://www.kommersant.ru/ doc/1621193 (дата обращения: 08.06.2018).

Колесников - Колесников А. Владимир Путин: «Даю вам честное партийное слово» // Коммерсант.ru. URL: http://www.kommersant.ru/ doc/1495411 (дата обращения: 08.06.2018).

Мономах-Мономах В. Верные путинцы-всего лишь реинкарнированные власовцы // Newsland. 
URL: http://newsland.com/news/detail/id/946690/ (дата обращения: 18.06.2018).

Общество синих ведерок-Общество синих ведерок атакуют боты, защищающие прайвеси чиновников // Газета.ru. URL: http:/www.gazeta.ru/ news/blogs/2011/06/08/n_1875261.shtml (дата обращения 08.06.2018).

Порошенко - Президент Украины Петр Порошенко объявил о намерении провести всенародный референдум о присоединении страны к HATO // Эхо Москвы. URL: http://echo.msk.ru/ news/1535562-echo.html (дата обращения: 06.06.2018).

Путин - Владимир Путин: «Для России характерна традиция сильного государства» // Сегодня.ру. Информационно-аналитическое сетевое издание. URL: http://www.segodnia.ru/news/116178 (дата обращения: 06.06.2018).

Репортаж со съезда - Репортаж со съезда: «Единую Россию» яйцом не раскололи // Аргументы и факты. AIF.RU. URL: http://gazeta.aif.ru/online/aif/ 1210/02_04(дата обращения: 18.06.2018).

Рискин - Рискин А. Анатолий Лисицын взял под козырек // Независимая газета. URL: http:// www.ng.ru/regions/2004-09-17/4_lisitsyn.html (дата обращения: 18.06.2018).

Сапожников - Сапожников Б. Жириновский дал урок мира // Газета.ru. URL: http://www.gazeta.ru/2003/ 03/24/zirinovskijp.shtml (дата обращения: 18.07.2018).

Сербицкий - Сербицкий Д. В Интернете набирает популярность фильм «Президент»: Путин рассказывает, как приструнил олигархов, о фразе «мочить в сортире», о США и террористах // Марийская правда. URL: http://www. marpravda.ru/news/vsja-respyblika/v-internetepoyavilis-fragmenty-filma-prezident-pu/ (дата обращения: 19.07.2018).

Троицкий - Троицкий А. Особое мнение // Эхо Москвы. URL: https:/echo.msk.ru/programs/ personalno/1953940-echo/ (дата обращения: 30.06.2018).

\section{REFERENCES}

Zarezina S.N., 2004. Recurrent Personal Meanings in Intercultural Communication (Based on the Articles about Russia in English Mass Media Discourse of 1991-2004). Cand. philol. sci. diss. Irkutsk. 236 p.

Krasnykh V.V., 1998. From the Concept to the Text (on the Issue of Text Psycholinguistics). Vestnik Moskovskogo universiteta. Ser. 9. Filologiya [Moscow State University Bulletin. Series 9. Philology], no. 1, pp. 53-70.
Leontyev A.N., 2000. Lectures on General Psychology. Moscow, Smysl Publ. 511 p.

Strelkova O.A., 2006. Modern Women's Political Discourse (Based on Verbal Portraits of Women-Politicians). Cand. philol. sci. diss. Kursk, Kursk. 183 p.

Chudinov A.P., 2009. Modern Political Communication. Ekaterinburg, Ural. gos. ped. un-t. 292 p.

Grice H.P., 1989. Studies in the Way of Words. Cambridge, Harvard University Press. 394 p.

\section{SOURCES}

Zhirinovsky V.V., 2011. LDPR (Liberal Democratic Party). Freaks. Moscow, LDPR Publ. 160 p.

Kamyshev D. Project “Well, wait!”. Kommersant.ru. URL: http://www.kommersant.ru/doc/1621193 (accessed 8 June 2018).

Kolesnikov A. Vladimir Putin: "I give you an honest party word". Kommersant.ru. URL: http:// www.kommersant.ru/doc/1495411 (accessed 8 June 2018).

Monomakh V. Faithful Putintsy - Only Reincarnated Vlasovites. Newsland. URL: http://newsland. com/news/detail/id/946690/ (accessed 18 June 2018).

The society of blue buckets is attacked by bots protecting the privacy of officials. Gazeta.ru. URL: http://www.gazeta.ru/news/blogs/2011/06/ 08/n_1875261.shtml (accessed 8 June 2018).

President of Ukraine Petr Poroshenko announced his intention to hold a nationwide referendum on the country's accession to NATO. URL: http:// echo.msk.ru/news/1535562-echo.html (accessed 6 June 2018).

Vladimir Putin: "The tradition of a strong state is characteristic of Russia". Segodnya.ru. Information and analytical online edition. URL: http://www.segodnia.ru/news/116178 (accessed 6 June 2018).

Report from the congress: "The United Russia" was not split by an egg. Argumenty $i$ fakty. AIF.RU. URL: http://gazeta.aif.ru/online/aif/1210/02_04 (accessed 18 June 2018).

Riskin A. Anatoly Lisitsyn took a visor. Nezavisimaya Gazeta. URL: http:/www.ng.ru/regions/2004-0917/4_lisitsyn.html (accessed 18 June 2018).

Sapozhnikov B. Zhirinovsky gave a lesson in peace. Gazeta.ru. URL: http://www.gazeta.ru/2003/03/24/ zirinovskijp.shtml (accessed 18 July 2018).

Serbitsky D. On the Internet, the film President is gaining popularity: Putin talks about how he reinvigorated the oligarchs, about the phrase "drenching in the outhouse", about the US and the terrorists. Mariyskaya Pravda. URL: http:// 
C.Н. Зарезина. Выражение личностного смысла в современном политическом дискурсе

www.marpravda.ru/news/vsja-respyblika/vinternete-poyavilis-fragmenty-filma-prezidentpu/ (accessed 19 July 2018).
Troitsky A. Dissenting opinion. Ekho Moskvy. URL: https://echo.msk.ru/programs/personalno/ 1953940-echo/ (accessed 30 June 2018).

\section{Information about the Author}

Svetlana N. Zarezina, Candidate of Sciences (Philology), Associate Professor of Department of English Philology, Irkutsk State University, Lenina St., 8, 664025 Irkutsk, Russia, zarezina@mail.ru, https:// orcid.org/0000-0002-1423-644X

\section{Информация об авторе}

Светлана Николаевна Зарезина, кандидат филологических наук, доцент кафедры английской филологии, Иркутский государственный университет, ул. Ленина, 8, 664025 г. Иркутск, Россия, zarezina@mail.ru, https://orcid.org/0000-0002-1423-644X 